\title{
OS USOS SOCIAIS DO DINHEIRO EM CIRCUITOS FILANTRÓPICOS. O CASO DAS "PUBLICAÇÕES DE RUA"
}

Ariel Wilkis

A literatura sobre filantropia aponta para a "mercantilização" das doações ${ }^{1}$ como um dos traços mais importantes das transformações recentes desse universo organizativo. Ao assimilarem cada vez mais as técnicas do marketing e da comunicação pública, as organizações filantrópicas realizam atualmente campanhas para vender um produto com o objetivo de arrecadar dinheiro para a causa que perseguem. Estas transformações são particularmente interessantes para que se reflita sobre a natureza das fronteiras entre as "transações mercantis" e as "circulações de dons"2 e, em especial, sobre o papel do dinheiro para marcar estes limites. Algumas perguntas se colocam: a monetarização crescente das transferências filantrópicas supõe a invasão das "transações mercantis" no universo das doações a ponto de eliminar a especificidade destas últimas ? $^{3} \mathrm{Ou}$, ao contrário, este processo responde à criação de "moedas especiais" (Zelizer 1989, 2005a) em que estão em jogo práticas, interações e rituais que marcam o dinheiro de origem filantrópica, atribuindo-lhe uma qualidade social sui generis ? $^{4}$

A relação entre dinheiro e dom pode ser ao menos rastreada nas diferentes posições de Malinowski (1986) e Mauss (1997) a respeito do uso da noção de moeda para denominar os objetos que circulam no Kula. Diferente de Malinowski, que rejeitava esta denominação, Mauss argumentava que os objetos "pessoais" ou "subjetivos" que circulavam entre os trobriandeses podiam ser denominados de moeda. Segundo Bloch (1989), esta distância em relação a Malinowski posiciona Mauss num terreno onde não existe uma distinção analítica clara entre o dinheiro e os objetos da troca de dons. Esta perspectiva, que não deixa de estar marcada pela imprecisão, ${ }^{5}$ tem a vantagem de nos obrigar a ter precauções em relação às teses que excluem necessariamente o dinheiro de determinados vínculos sociais ou esferas da troca. As teses que opõem "transações mercantis" e "circulações de dons" — 
e que geralmente associam o dinheiro às primeiras, tornando-o incompatível com os princípios das segundas - foram questionadas por estarem ligadas a um discurso "essencialista" da antropologia (Carrier 1992), em função de se apoiarem em uma representação "etnocêntrica" da "modernização" (Weber 2000) e, finalmente, por assinalarem sua natureza ideológica (Parry 1986).

Estas questões relacionadas ao dinheiro, às "transações mercantis" e à "circulação de dons" serão discutidas a partir de pesquisa realizada em uma organização da cidade de Buenos Aires que edita uma revista vendida por pessoas "sem teto" e desempregadas. A organização Hecho en Buenos Aires (HBA) foi criada no ano 2000, tomando como modelo a experiência inglesa de uma revista escrita por profissionais e vendida por homeless. A questão monetária no caso da publicação de rua ${ }^{6} \mathrm{HBA}$ apóia-se em dois níveis: por um lado, a organização incentiva potenciais compradores para que adquiram a revista como gesto de apoio aos vendedores, argumentando que a venda é um meio de inserção social; por outro lado, os mesmos vendedores reforçam publicamente este pedido em suas interações com os lugares onde oferecem a revista.

Meus dados etnográficos me levam a problematizar a idéia de que o meio de pagamento define integralmente a natureza das transferências. Meu esforço consistirá em compreender como se produzem as passagens entre diferentes tipos de transferências, ainda que aquilo que se troca seja sempre dinheiro versus revista. Neste sentido, a etnografia das cenas de compra-venda da publicação de rua me permite intervir nas discussões sobre a fronteira entre as "transações mercantis" e as "circulações de dons", e o papel do dinheiro na sua definição. ${ }^{7}$

Refletirei também sobre a oposição dinheiro e moral. Ao se destacar seu papel de equivalente geral, meio impessoal ou vetor de racionalização das relações sociais, o dinheiro foi conceitualizado pela literatura sociológica e antropológica em oposição aos laços morais e afetivos que ligam as pessoas. Dito de maneira breve: dinheiro e moral parecem pertencer a mundos sociais "hostis" (Zelizer 2005b). Várias pesquisas (Bloch \& Parry 1989; Zelizer 2005a e 2005b; Weber 2000) apontam a necessidade de se colocar entre parênteses esta hostilidade e convidam a interrogar os usos sociais do dinheiro a partir de seus componentes morais. Esta indagação será feita no contexto específico de transferências de dinheiro destinadas à ajuda, como é o caso da circulação monetária que se produz por conta da publicação de rua HBA.

O recorte temporal da pesquisa é o período que vai da origem da organização, no ano 2000, até fins de 2004. Realizei entrevistas com os vendedores e os compradores da publicação, e observei os cenários onde ambos se 
encontram. Entrevistei os membros fundadores, os diretores e os assistentes sociais da organização. Por último, analisei o conteúdo das revistas e das fichas de inscrição que os vendedores preenchem quando entram na HBA.

\section{As publicações de rua na cidade de Buenos Aires: a promoção de uma troca filantrópica}

No final dos anos 90, calcula-se que existiam aproximadamente 150 publicações de rua em diferentes lugares do mundo. ${ }^{8}$ Estabeleceram-se redes mundiais, regionais e nacionais que as englobam. No entanto, as suas trajetórias foram díspares, desaparecendo ou tentando sobreviver em alguns casos e consolidando-se em outros. ${ }^{9}$ Originárias da Europa e dos EUA, as publicações de rua expandiram-se para os outros continentes (África, Ásia e América Latina) no fim da década de 90 e princípios da seguinte. ${ }^{10} \mathrm{O}$ perfil social dos vendedores é heterogêneo: pessoas "sem teto", desempregados, imigrantes ilegais, refugiados etc. Muitas dessas publicações são empreendimentos gerados por instituições ou serviços sociais que vinham trabalhando na assistência social (por exemplo, Factor $S$, de Montevidéu, que pertence a um Centro Franciscano; Big News, de Nova York, ligada a um centro de pessoas "sem teto"; e ainda L'Itineraire, de Montreal, que surgiu a partir de um restaurante econômico para os "sem teto").

Sem vínculos com outras organizações ${ }^{11}$ que avalizem a iniciativa ou que aportem algum tipo de capital, seja em termos econômicos, seja no de experiência com o trabalho social, os fundadores da Hecho en Buenos Aires provinham de diferentes trajetórias: alguns estavam ligados ao jornalismo, outros ao trabalho social, ou simplesmente viram-se atraídos pela convocação de uma das fundadoras. A primeira etapa da organização consistiu em estabelecer contatos com a publicação inglesa Big Issue e outras revistas do exterior, visando definir o formato da publicação e a estrutura organizativa, bem como começar a vincular-se aos futuros vendedores.

Um impulso importante para o lançamento foi dado pelo British Council (Conselho Britânico) através de um subsídio que serviu de capital inicial para a montagem do projeto e do primeiro número da revista. Num primeiro momento, os membros da organização contataram os futuros vendedores, tanto em áreas onde habitualmente pessoas dormem nas ruas (como a Plaza Congreso), quanto através de visitas a diferentes "abrigos"12 e igrejas. $\mathrm{Na}$ apresentação da revista aos potenciais vendedores, enfatizou-se a idéia de que estava sendo oferecida uma proposta de trabalho. O lançamento do primeiro número da revista foi em junho de $2000 .{ }^{13}$ 
As primeiras 10 revistas que os vendedores recebem quando entram para a organização não têm custo. A partir daí, pagam por elas um valor que varia entre $10 \%$ e $30 \%$ do preço de capa. A primeira tiragem de junho de 2000 foi de 5 mil. Com picos de até 40 mil revistas, esse número estabilizou-se em 25, 30 mil exemplares no final de 2004. O crescimento do número de vendedores - ainda que irregular, mas constante em determinados períodos e a venda de exemplares foram acompanhados pela divulgação da HBA em diferentes meios de comunicação, através de notas, reportagens etc. Esta presença permitiu que o projeto se tornasse cada vez mais conhecido, fazendo com que a organização recebesse ofertas de trabalho voluntário e algumas doações. Entre junho de 2000 e dezembro de 2004, cerca de 1.600 pessoas inscreveram-se na organização, mas o grupo regular de vendedores estabilizou-se entre 200 e 250, apresentando um nível importante de rotatividade. ${ }^{14}$

A idéia original da HBA assentava-se sobre dois pilares: transformar-se em uma empresa social e oferecer possibilidades de inserção social através de uma proposta de emprego. Vejamos como estas concepções aparecem nos relatos dos membros fundadores da HBA:

Estava dirigido a pessoas da rua, excluídas. Fomos a quase todos os abrigos com o número 1 da revista. Fomos ao abrigo Felix Lora para oferecer às pessoas uma oportunidade de trabalho. Isto sempre foi colocado como uma oportunidade direta e concreta, ninguém faria a mediação entre o grupo promotor e os vendedores. O grupo da organização que estava se formando era quem ia entregar revistas, não havia necessidade de que alguém mediasse. Nossa lógica era: essas pessoas estão vivendo num abrigo porque não têm oportunidade de trabalho, então vamos oferecer a elas uma oportunidade de trabalho através da qual possam recuperar sua auto-estima e tornar-se independentes (Membro do grupo fundador e diretora da HBA; há quatro anos na organização).

Uma das chaves de impulso da empresa social é sua legitimação através da idéia do empoderamento. Segundo esta concepção, o trabalho permitiria aos destinatários "ativarem mudanças positivas em suas vidas" em termos de recursos materiais e em relação à auto-estima.

O que empresa social faz é abrir compartimentos estanques e incorporar essas pessoas ao mercado de trabalho através da participação, da cultura do trabalho e do empoderamento econômico, que é o que estamos fazendo (Membro do grupo fundador e diretora da HBA; há quatro anos na organização). 
É interessante considerar que esta "filosofia" — que combina as categorias de inserção, empresa social e empoderamento - expressa uma troca singular que dá conta da natureza filantrópica da proposta das publicações de rua. De fato, se a caridade se caracteriza pela despreocupação em relação à forma com que se usa o dinheiro recebido, na filantropia o receptor deve devolver o recebido em termos de sua subjetividade, caráter ou cuidado pessoal (Ruonavaara 1997:283-284). Os termos desta troca seriam os seguintes: uma das partes da relação, neste caso aqueles que representam a organização, tem um projeto sobre como deveria ser a vida dos vendedores; estes últimos o levariam adiante, o que significaria uma mudança identitária em função dos ideais que o projeto apresenta. Nesta troca, o dinheiro cumpre um papel central.

O sentido da circulação monetária — a transferência de revistas aos vendedores a um custo baixo para que eles possam conseguir dinheiro e tornar a comprá-las e, assim, sustentarem as suas necessidades básicas - é um dos elementos nos quais se baseia, em geral, a "troca filantrópica" das publicações de rua, e da HBA em particular. Segundo esta visão, se a circulação se realizar sob os termos desta troca, os vendedores começarão a recuperar o "controle de suas vidas, a elevar sua estima, a ganhar independência". Como diz uma de nossas entrevistadas, "o que você está dando é uma ferramenta para que ele tenha uma renda, e isto potencializa a possibilidade de poder gerar a autonomia relativa da pessoa", portanto, a máxima é "receber uma renda, capitalizar-se e empoderar-se economicamente" (Assistente social da HBA; há três anos na organização).

Uma das funções da HBA no circuito filantrópico é dar a conhecer que esta troca está se realizando para ganhar o apoio dos compradores. Como veremos, a circulação monetária é apresentada como um dos princípios que legitimam e diferenciam os propósitos da organização. A interpelação aos compradores para que apóiem estes objetivos se sustenta nas "formas" com que se deve dar e receber o dinheiro.

A revista tem 30 páginas e foi editada em branco, preto e vermelho até o número 40 (dezembro de 2003), quando se começou a utilizar mais cores. A maioria das matérias foi escrita por jornalistas profissionais ou semiprofissionais. Em alguns números, incluem-se matérias de outras publicações de rua. Além das seções centrais - informes, entrevistas ou notas - são publicados comentários sobre espetáculos, livros, discos, e há uma seção de anúncios. Duas páginas trazem entrevistas com os vendedores, ou estes publicam poemas e desenhos. A capa das revistas tem dois claros indícios das características da publicação e de seus objetivos: o seu nome vem acompanhado da frase "saindo da rua" e contém, ainda, o valor em dinhei- 
ro que o vendedor obtém em cada revista vendida. Na primeira página são mencionados os objetivos da organização; pede-se ao público que compre de vendedores autorizados e informa-se que estes devem portar sempre a credencial da organização e mostrá-la a quem o solicite. Também consta um número de telefone para que em face de qualquer inconveniente seja possível comunicar-se com a organização. Assinala-se que os vendedores não podem pedir dinheiro nas ruas como "resultado de sua condição de vendedor", que eles são pessoas marginalizadas, e a venda da revista é o primeiro passo para a sua reinserção. Em alguns números, mencionam-se as atividades que a organização oferece: oficinas, serviços médicos, terapias de apoio. Estas fórmulas foram mudando ao longo do tempo, mas a divulgação dos objetivos e do papel da organização se manteve.

A apresentação do código de conduta nas primeiras páginas da publicação formaliza, de maneira muito precisa, em que condições a revista deve ser vendida, isto é, a "forma" aprovada de receber dinheiro no contexto da "troca filantrópica". O código de conduta estabelece que é proibido: a) estar sob efeito de álcool ou drogas durante a venda; b) brigar ou discutir com outro vendedor ou com outras pessoas; c) não ter a credencial da revista; d) mendigar enquanto exibem a credencial da HBA; e) ter um comportamento ofensivo que possa desacreditar o trabalho de outros vendedores e da organização. Estes são os principais traços da "troca filantrópica" promovida pela publicação de rua HBA. Como vemos, a "forma" de transferência de dinheiro aos vendedores é um de seus pilares.

\section{Espaço e tempo de trabalho}

A jornada de trabalho dos vendedores começa com a ida até a sede da HBA para comprar as revistas que serão vendidas durante o dia. A espera do novo número costuma estar cercada de grande expectativa, já que a queda das vendas nos últimos dias do mês gera a necessidade de ter um novo produto a oferecer. Os vendedores telefonam para averiguar quando sai o próximo número, aproximam-se da sede. É um momento de muita euforia e agitação. O novo número é esperado, a venda deve continuar, e sem revistas não há vendas. Quando é lançada a nova publicação, costuma ser feita a maior compra de revistas; à medida que o mês vai chegando ao fim, as aquisições vão diminuindo.

A organização atribui aos vendedores alguns pontos para vender a revista, em geral localizados no centro de Buenos Aires, nos cruzamentos de avenidas de muita movimentação, ou em lugares de lazer (os bairros 
"porteños" de San Telmo ou Palermo, por exemplo). Também é comum aproveitar eventos especiais em que haja concentração de pessoas, como manifestações ou shows, ou ainda em transportes públicos, como trens, metrôs ou ônibus.

Para que os pontos não sejam invadidos por outros agentes e que, além disso, esses lugares sejam identificados com o vendedor da revista, é necessário "cuidar do espaço". Este imperativo supõe, para os vendedores, a combinação de práticas de sociabilidade: estar preparado para o contato com diferentes pessoas; manter diálogos com os compradores; estar disposto a responder às perguntas que estes possam fazer; gerar certa cumplicidade com outros vendedores ambulantes para compartilhar recursos ou informação; ganhar a confiança das pessoas que regulam o acesso a determinados âmbitos: porteiros, policiais, empregados do comércio, agentes de segurança privada etc. "Cuidar do espaço" também requer disposição física. Vender a revista na rua é um trabalho cansativo, pois é preciso ficar de pé durante várias horas ou percorrer ruas; levar as revistas sempre na mão ou em uma bolsa; ir oferecendo às pessoas ou erguer o braço mostrando-as e gritando o nome da publicação. Estas atividades tornam-se ainda mais cansativas quando quem as realiza dormiu poucas horas, passou a noite na rua ou está mal alimentado.

Os registros de campo são bem expressivos a esse respeito: Juana ${ }^{15}$ relata que na última noite não dormiu, ficou sentada algumas horas em um bar do bairro do Once que fica aberto a noite toda; conta para mim que para passar a noite fica pulando de lugar em lugar — casa de amigos, bares ou simplesmente não dorme. Prefere não ir aos abrigos, porque "estão cheios de loucos" (anotações de campo de entrevista com Juana, 27 de maio de 2005). Diego está com a cara cheia de hematomas, evidentemente não passou uma "boa noite". Conta que ontem foi seu aniversário, que vendeu todas as revistas que lhe deram na HBA e que depois não se lembra de nada. Faz referência ao fato de que bebeu muito álcool. Não há dúvida de que teve uma briga séria, sua cara está toda inchada pelos socos que recebeu. No final, me diz: "Eu não posso ir vender revista com esta cara" (anotação de campo de entrevista com Diego, 8 de setembro de 2004). Finalmente, "cuidar do espaço" é um imperativo que às vezes se cumpre através da força; as brigas entre os vendedores pelos pontos mais rentáveis dão conta desta exigência.

A regulação do tempo de trabalho realiza-se em função do fluxo dos transeuntes: aqueles que vendem em locais de lazer o fazem preferencialmente à noite; os vendedores que trabalham no centro preferem fazê-lo durante o dia e nas horas que os empregados entram ou saem de seus escritórios. Os momentos de alta circulação são ocasiões que não podem ser perdidas e requerem um grande esforço físico e mental. Também se encontram ven- 
dedores que, além da revista, vendem outros produtos na via pública, como lencinhos ou flores. Estas atividades paralelas servem para complementar a renda que a revista oferece.

Um dos aspectos mais importantes da venda é a sua irregularidade ao longo do mês. Nas duas primeiras semanas depois do lançamento de um novo número é quando melhor se vende. Depois, a venda começa a decair, os compradores habituais já obtiveram a revista e é necessário vendê-la a quem não a conhece ou não a compra regularmente. No fim do mês, é possível ver menos vendedores nas ruas, ou encontrá-los em busca de outros trabalhos, ou ainda diminuindo as horas de venda porque se torna desnecessário investir o mesmo tempo dos primeiros dias. Para alguns vendedores, a venda é uma alternativa esporádica e irregular que pode ser abandonada e retomada depois de um intervalo.

\section{Cenas de troca}

Em termos editoriais, a venda da revista não é nada desprezível se comparada a outras publicações "comerciais". Este indicador quantitativo aponta que pelo menos 25 a 30 mil pessoas "compram" a revista dos quase 250 vendedores. Seria suficiente dizer que estamos diante da transação de um produto entre compradores e vendedores para compreender o sentido da troca? A mediação monetária seria suficiente para atribuir-lhe o adjetivo "mercantil"? Devemos abandonar a fórmula da "troca filantrópica" para nos referirmos a ela? Finalmente, qual é a fronteira entre as "transações mercantis" e as transferências sob o registro de dons? A melhor maneira de abordar estas questões é descrevendo as transações entre vendedores e compradores e, em seguida, sistematizar meu entendimento deste fenômeno como uma "troca filantrópica" específica, compreendendo aí o papel do dinheiro.

\section{Cena (1)}

Estou com José, 28 anos, desde as 15 h30 no seu ponto, ao lado da entrada do metrô, em uma avenida central de Buenos Aires. Seu ritmo de trabalho está pautado pelos horários de chegada dos trens: de três a cinco minutos. São momentos de grande intensidade, porque os possíveis compradores se amontoam na saída do metrô e José fica parado diante deles. Quase não apregoa a revista, somente menciona seu nome. Durante o refluxo das pessoas, começamos a conversar. De repente, José sai correndo, atravessa a avenida e conversa com uma senhora; quando volta, comenta comigo: "Hoje ela disse que não, mas ela sempre compra". 
Várias pessoas passaram por nós e cumprimentaram José, mas somente duas compraram a revista, e o fizeram sem trocar palavras além do pedido do exemplar e da entrega do dinheiro. Quando observo que o dia não é muito bom no que se refere à venda, pergunto a José por que não vai para outro ponto, e ele me responde: "Aqui já me conhecem. Tenho minha clientela. Se eu vou embora daqui, tenho que começar do zero". Esta frase me lembra a conversa que tive com outro vendedor, Daniel, 31 anos, que havia comentado comigo que suas vendas eram mais baixas que as de José - que foi quem o levou para a HBA - "porque não era conhecido" e carecia das técnicas necessárias para encarar e persuadir os compradores, habilidades que via em seu companheiro no momento da venda.

Na última vez em que estive com José, ele havia dormido numa praça. Nesse dia, havia pouca gente na rua. Ele estava meio decepcionado com as vendas e achava que em pouco tempo conseguiria um trabalho entregando publicidade na rua. Quando deixei de ver José no seu ponto, lembrei da frase que resumia a sua decepção com as vendas e o que ela supunha. "Todos dizem 'eu gosto de você', mas ninguém te oferece um trabalho", disse-me ele, referindo-se aos compradores.

\section{Cena (2)}

Roberto tem 41 anos, trabalhou como fotógrafo até que lhe roubaram todo o seu equipamento de fotografia e não pôde continuar com seu ofício. Divide um apartamento com um tio e há um ano vende a revista. Seu ponto é na porta de um bar que fica no cruzamento de duas avenidas importantes da cidade, próximo ao Congresso Nacional. A segunda vez que me encontrei com ele tinha sido um bom dia: vendera 26 revistas. Mas, na maioria dos casos, as vendas são bastante irregulares ao longo do mês. Roberto me conta que escolheu esse ponto porque - diferente da esquina em frente, onde fica um supermercado - "as pessoas saem [do bar] relaxadas". Outros vendedores também afirmam que os melhores lugares para vender são os parques e as praças durante os fins de semana, pois as pessoas estão mais descontraídas.

No segundo dia de observação, escuto uma conversa entre Roberto e um comprador. O jovem diz: "Hoje você está bem, está pra cima. Você conseguiu pra mim a outra revista?". Eles continuam conversando e Roberto pergunta ao rapaz: "Nos vemos amanhã?". Registro que Roberto me conta, ao mesmo tempo, que este rapaz lhe deu um casaco. No outro dia, Roberto se lembraria que lhe vendeu números atrasados porque este comprador é professor de literatura. Ao final desta jornada, me pede que na próxima sexta-feira eu não o visite no seu ponto, porque "não quero que ninguém 
me incomode". Esse último dia da semana é uma jornada-chave para a economia dos vendedores, o atraso do novo número afeta sua renda e é preciso recuperar o tempo perdido.

\section{Cena (3)}

Mario tem 59 anos e vive com sua ex-mulher na mesma casa porque não podem alugar cada um a sua. Caminha pela rua Florida - a principal rua de pedestres da cidade - erguendo o braço com a revista na mão. Ele apregoa: "HBA, algo mais que uma revista, um projeto social e cultural para pessoas excluídas. Gratifique seu coração. A revista dos 'sem teto', uma ferramenta de trabalho". Na capa da revista do mês aparece o guitarrista de uma das bandas de rock mais populares da Argentina. Mario comenta que mostra bem a revista porque notou que os jovens que passam se interessam pela capa. Em uma das observações, durante a primeira semana de dezembro, Mario tinha vendido 20 revistas entre $10 \mathrm{~h} 30$ e 17h. Vejo que Mario se aproxima de outro vendedor da HBA que se "meteu" no seu ponto e, quando volta, me diz: "A rua é uma guerra". Lembro-me do comentário de outro vendedor: "Mario se mata para manter sua imagem e os 'encrenqueiros' (referindo-se aos vendedores que o incomodam em seu ponto) vão lá e a detonam".

\section{Cena (4)}

Realizei observações em duas linhas de metrô durante diferentes momentos do meu trabalho de campo. Os vendedores da HBA circulavam pelos vagões e deixavam as revistas no colo dos passageiros do metrô sem dizer nada. Diante da minha pergunta sobre esta modalidade, um jovem vendedor me disse: "Eu somente a deixo [a revista], não faço uma novela".

\section{Cena (5)}

Estou próximo à sede da HBA quando um vendedor se aproxima para me oferecer um exemplar. Digo-lhe que já tenho o último número. Agressivamente ele me pede um trocado; diante desta situação decido dar-lhe 1 peso. Outras anotações de campo registram cenas nas quais alguns vendedores se aproximam de prováveis compradores. Quando se recusam a comprar, solicitam algum tipo de ajuda.

Por que documentar estas cenas? Que propriedades elas têm em comum e quais as distinguem? Para avançar na compreensão será necessário superar um primeiro obstáculo. Como argumenta Florence Weber (2000), a presença ou a ausência de dinheiro não define necessariamente uma transação como mercantil. Esta advertência permite evitar a idéia de que estamos diante de um formato unívoco de transação. Mas se colocamos entre parênteses 
este aspecto das transações, notaremos outros elementos que nos permitem compreender a natureza delas. Segundo Florence Weber, o entendimento de uma transação depende da maneira pela qual se articulam essas duas dimensões-chave que, desde Mauss (1997) até nossos dias, são a fonte de inteligibilidade de todas as trocas sociais: a dimensão-coisa e a dimensãopessoa. Como se articulam estas duas dimensões nas descrições de nossas cenas? Como se organizam estas últimas em função das qualidades das "pessoas" ou das "coisas"?

Seguindo Florence Weber (2000), consideramos que as transações mercantis se definem como interações afetivamente neutras, sem prolongamento no tempo, e nas quais as qualidades sociais e pessoais das partes estão postas entre parênteses. Por outro lado, a circulação de dons possibilita um encadeamento de interações que vincula as pessoas. As "coisas" transferidas servem de suporte às relações entre as "pessoas". A seguir, compreenderemos como as cenas de troca descritas adquirem sentido ao terem como referência estas indicações que diferenciam as "transações mercantis" e as "circulações de dons", apoiando-se principalmente nas "coisas", nas "pessoas", ou nas duas ao mesmo tempo.

Para cumprir este objetivo, reconstruirei os diferentes pontos de vista dos vendedores e dos compradores sobre estas cenas de troca: me deterei nas maneiras de nomear as transferências e naqueles que participam delas; veremos como elas são associadas e diferenciadas de outras "formas" de fazer circular o dinheiro; mostrarei os significados atribuídos aos objetos para traçar tais diferenças e semelhanças; por fim, darei elementos para compreender os sentidos das transferências monetárias que estão ligadas à ajuda no caso da publicação de rua HBA.

\section{"Transações mercantis", "circulação de dons" e dinheiro}

As flutuações nos níveis de venda - de cada vendedor e do conjunto da tiragem mensal - costumam estar ligadas ao conteúdo da revista e, principalmente, à capa de cada uma. Antes do lançamento de um número, os vendedores estão ansiosos sobre quem será o personagem publicado na capa, já que disso depende a melhoria das vendas para além dos compradores habituais. Às vezes, acontece certo descontentamento entre os vendedores, quando é publicado na capa algum tema ou personagem que não vende muito. ${ }^{16}$

Há vendedores que consideram a revista um produto como qualquer outro que se vende nas ruas. "Só muda a palavra: de pilha para revista HBA, 
porque você diz as pilhas 'Energizer', e é o mesmo para mim que dizer revista HBA. Para mim é a mesma coisa vender este copo, esta xícara e a revista. É um trabalho como qualquer outro. Fui vendedor durante muitos anos, sei o que é venda" (Vendedor da HBA, 47 anos).

Como mostra este comentário, os vendedores podem equiparar a revista a qualquer outra mercadoria e, através desta operação, "apagar" as marcas que sugerem a especificidade do produto que oferecem. Ao realizarem esta equiparação, conectam sua situação atual com outras experiências de trabalho - próprias ou alheias - e podem falar de si mesmos simplesmente como vendedores, em lugar de se auto-identificarem como vendedores do jornal de rua HBA.

Nesta maneira de apresentar o produto e a atividade, a transação monetária é narrada pelos vendedores de tal forma que não restam dúvidas sobre a semelhança com outras relações mercantis.

O mendigo pede. Você não está pedindo; está pedindo 1.50 pesos em troca de algo, então, você está comercializando. Por isso, você deve andar sempre com a sua identificação, que tem o número de vendedor que te habilita, porque você está comercializando algo, está cobrando por isso, não está dando de presente. Então, o cliente que compra tem o direito de saber se você está autorizado a comercializar algo na via pública ou não, e quem te autorizou a fazê-lo, por isso não é mendicância. O preço que você pede pela revista está escrito na capa, não é o que te dá na telha (Vendedor da HBA, 44 anos).

Neste comentário é possível destacar uma série de elementos que acentuam o fato de que os vendedores estão comercializando um produto. Em primeiro lugar, enquanto os mendigos pedem e não dão nada, eles recebem dinheiro em troca de uma revista. Em segundo lugar, as referências à autorização e ao direito dos compradores de pedi-la apresentam a transação dentro de um marco de aparente formalidade. Em terceiro lugar, o preço é um dado objetivo que aparece na capa da revista; os vendedores não decidem arbitrariamente quanto dinheiro solicitar. Como se observa, estes elementos permitem afastar os erros de interpretação sobre a natureza da transferência: trata-se de uma transação mercantil como as demais.

O relato que se segue apresenta uma continuidade com os argumentos que equiparam a venda da revista a outras transações mercantis de rua mas, ao mesmo tempo, é preciso atentar para a maneira como o vendedor introduz outras referências à sua própria identidade, aos produtos que circulam e às razões de dar e receber entre compradores e vendedores. 
Eu não estou pedindo dinheiro, estou vendendo algo, um produto, e se você quiser comprar, você compra. Como você sabe que ela tem um fim solidário, você pode me dizer: "Olha, eu não vou comprar a revista porque não a leio, mas tenho uma bolsa de roupas de um parente". E bom, se você tá precisando, o que você vai dizer? Não? É um orgulho meio idiota rejeitá-la, se somos pessoas em situação de rua, e todo mundo entende isto assim. Tem gente que quando eu digo: "Me compra uma revista que é para eu comprar um sanduíche", me responde: "Eu te compro o sanduíche, mas a revista não", e bom, a gente aceita (Vendedor da HBA, 39 anos).

Esta narrativa altera a linha de descrição que vínhamos fazendo sobre as trocas entre vendedores e compradores. Os significados postos em jogo em muitas dessas transações "destoam" de um registro exclusivamente mercantil; a troca enquadra-se num contexto em que todos sabem que os vendedores são pessoas em situação de rua e que a venda tem fins solidários. Este reenquadramento produz uma mudança na maneira com que os objetos intervêm nas narrativas das trocas. Agora, eles não servem para equiparar a venda da revista a outras atividades de venda na rua. Esta transformação que se opera no significado dos objetos indica que atravessamos a fronteira entre diferentes formas de transação. Observamos, assim, que é possível haver uma separação entre a troca de dinheiro pela revista e a interação entre vendedores e compradores. De fato, esta última pode se organizar para além da transferência de objetos equivalentes e, inclusive, no marco de uma circulação unilateral de recursos (roupas, alimentos). O objeto e seu preço ${ }^{17}$ não constituem necessariamente o centro das interações.

Poderíamos nos deter neste ponto e responder às nossas perguntas entendendo que a fronteira entre "transações mercantis" e "circulação de dons", no nosso caso, define-se pela presença ou ausência destes objetos, em especial do dinheiro. No entanto, mesmo quando a revista e o dinheiro estão organizando a interação entre vendedores e compradores, ambos deixam de servir de base para o ponto de vista que associa estas trocas às transações mercantis como as demais. Dois trechos de entrevistas nos permitem avançar nesta interpretação. O primeiro insiste na ruptura da equivalência entre os objetos trocados; o segundo, na ausência de um valor de uso do produto que se vende. Em ambos os casos, fica claro como as propriedades dos objetos da troca estabelecem uma distância entre vender a publicação de rua e vender outro produto.

Tem gente que te dá 5 pesos por uma revista. Não vale 5 pesos, mas por que eles te dão 5 pesos? Por quê? Porque você está vendendo Hecho en Buenos Aires. 
Se você estivesse vendendo três isqueiros por 1 peso, não te dariam 5 pesos por eles (Vendedor da HBA, 28 anos).

Quem compra pilha é quem precisa de pilha. Tem gente que não precisa da revista, ou não se interessa por ela. Bom, aí está a exceção, é onde você tem que entrar com simpatia, falando bem, e explicar a eles. Aquele que vai comprar cigarros é porque precisa, ou aquele que vai comprar um rádio ou comprar um relógio é porque precisa. Esta é a diferença (Vendedor da HBA, 55 anos).

Se os vendedores podem receber mais dinheiro do que o preço fixado na capa e, além disso, a venda da revista não depende de uma necessidade ou de um interesse, cabe a pergunta: Pelo que os compradores estão pagando? Para responder a esta pergunta, reconstruamos seu ponto de vista sobre a troca através de uma compradora da HBA, que nos relata da seguinte maneira o seu primeiro contato com um vendedor da revista:

No início ele me ofereceu a revista e eu comprei; pensei: compro e pronto, posso voltar ao trabalho. Depois, li sobre de que se tratava, e ele me contou mais ou menos como era a sua vida, o que era a revista para ele, e foi aí que eu pensei que pelo menos ele está fazendo alguma coisa; com a idade que ele tem, não dá pra ficar na porta de uma igreja pedindo comida (Compradora da HBA, comerciante, 40 anos).

Uma transação banal, que se realizava para não perder tempo, adquire outro sentido quando a compradora se detém para ler o conteúdo da revista e escutar o vendedor. A clivagem se produz quando entra em jogo a comparação com outras alternativas para obter meios de subsistência: o vendedor não fica na porta de uma igreja pedindo comida, ele pelo menos faz alguma coisa. Dando continuidade a esta comparação, encontramos outros testemunhos.

Compro a revista para ajudar, e gosto de comprar, eu decido a quem ajudar. Não sou de dar dinheiro a todo mundo que pede, mas estas pessoas estão vendendo alguma coisa e você vê que eles ficam muitas horas trabalhando, molhados, morrendo de frio [...] por um trocado (Compradora da HBA, médica, 25 anos).

É diferente daqueles que só pedem. Os vendedores tentam fazer alguma coisa, é outra atitude, não é provocar pena. Eles se esforçam pra ganhar seu dinheiro (Comprador da HBA, estudante universitário, 21 anos). 
Nesses testemunhos, o universo de pessoas "necessitadas" é classificado - e hierarquizado - em duas categorias morais vinculadas a determinadas circulações de recursos: aqueles que dão pena pedindo e aqueles que se esforçam trabalhando. A venda da revista repara circunstancialmente uma trajetória negativa, e esta reparação é interpretada a partir da categoria moral do esforço ligada à noção de trabalho.

Na maioria das vezes, esta revista tirou eles da droga, levou eles de volta para sua família; são pessoas que querem sair da situação em que estão (Comprador da HBA, empregado do comércio, 26 anos).

Cada um tem sua loucura, sua história, mas ela tira todos eles de um monte de coisas, ajuda a todos... O trabalho é saúde (Compradora da HBA, empregada, 40 anos).

É interessante como a noção de trabalho volta para descrever a transação. Desta vez, ela é mobilizada pelos compradores para construírem seu ponto de vista sobre os vendedores e a transação. Este ponto de vista apóiase na noção de trabalho para enfatizar a distância moral entre as atividades dos vendedores e daqueles que pedem. A seguinte transcrição da carta de um leitor permite observar como se põe em jogo esta classificação:

[Quero compartilhar duas emoções]. A primeira [...] aproximo-me de um vendedor e lhe peço um exemplar pagando com 2 pesos; quando ele me diz que não tem troco, eu sugiro que ele fique com o troco; o vendedor me estende um segundo exemplar, dizendo: melhor levar outro para um amigo. Aí compreendi a função mais importante da revista, restituir o sentido do trabalho (Revista HBA, n.12).

A emoção que a compradora deseja compartilhar tem sua origem na recusa do vendedor ao dinheiro sem contrapartida. Este gesto afirma a natureza da transação e, sobretudo, a forma com a qual os vendedores obtêm seu dinheiro. Tal emoção, podemos supor, tem origem na surpresa que este gesto traz, não era o esperado; só quando ele se produz é que a compradora descobre que a "função da revista é restituir o sentido do trabalho".

Esta circulação monetária hierarquiza "boas" e "más" formas de ganhar a renda: aqueles que recebem o dinheiro trabalhando diferenciam-se "meritoriamente" daqueles que o fazem pedindo. Portanto, o dinheiro transferido destina-se a valorizar um esforço, a recompensar uma "vontade", ao invés de circular pelo valor de uso do objeto recebido. No caso de não terem interesse 
pela revista, os compradores costumam recebê-la de toda maneira para não se mostrarem descorteses com os vendedores. Estes, quando recebem um dinheiro extra, tratam de entregar outra revista, dando a entender que não obtêm dinheiro de maneira gratuita, mas sempre através de alguma contraprestação, como vimos no relato da carta do leitor que comentamos. Em ambos os casos, trata-se de "cuidar das formas" mínimas que se referem a uma compra-venda, as quais permitem que os vendedores se diferenciem daqueles que pedem.

\section{Circulação monetária e vínculos pessoais}

Os usos sociais do dinheiro ligados às expectativas, às emoções e às classificações dos compradores informam o que é próprio a essas transações monetárias: a subordinação do produto à identidade social dos vendedores. Ao aprofundarmos a análise das cenas de trocas, encontramos indicadores que remetem à dimensão biográfica da identidade dos vendedores: nomes pessoais para chamar os vendedores, conhecimento de eventos da sua vida, piadas compartilhadas, relação com familiares, entre outros. O relato que se segue reflete essa dimensão das trocas através da ótica de uma das vendedoras da HBA.

Estou muito contente porque as pessoas que viajam no metrô são maravilhosas, pelo menos comigo, eu tenho clientes que todo o mês compram a revista comigo; são sobretudo rapazes da faculdade. Se lhes falta um número da revista, eles me pedem, e às vezes eu consigo [...] Fico conversando com eles. A menina que te falei, no fim do ano me surpreendeu, trouxe uma mochila cheia de coisas. Eu perguntei: "De onde vem isso?", e ela me disse: "Não fique chateada, nem se ofenda, você merece". Então fiquei quieta, e disse: "Estou muito agradecida". Quando cheguei na minha casa e abri a bolsa, eu quis morrer. Dois dias depois, quando a vi, eu lhe disse: "Te agradeço, que Deus te dê tudo, que você possa cruzar todos os mares que precisar, que você se forme logo". Ela é um amor. Também tem outra menina por aqui que estuda nessa mesma faculdade. As pessoas que passam por aí nunca disseram nada. Eu nunca vendi assim, e quando vendo uma revista fico muito agradecida porque essas pessoas estão me ajudando [...] No outro dia passei mal com minha hérnia, essa menina disse: "Quer que eu chame um médico?", e ficou comigo um tempo, depois chamou o vigia e chamou uma ambulância. Te conto que todos os meses levo a revista naquela livraria. Outro dia fui à livraria e disse: "compra uma revista da Hecho", e me disseram: "Sim, sim. Antes vinha uma menina, mas agora 
compro de você, você é mais velha e precisa mais". O rapaz da loteria também, e depois também tem as moças que todos os meses me dizem: "Maria você me trouxe a revista?" (Vendedora da HBA, 72 anos).

Estas trocas supõem práticas contínuas que mantêm a regularidade do contato entre ambos. Por exemplo, os vendedores conseguem o consentimento dos compradores para levar as revistas todos os meses às suas casas ou aos seus lugares de trabalho. É comum que aqueles vendedores que mantêm seu ponto consigam estabelecer certa familiaridade com algumas pessoas do bairro ou transeuntes. Nas cenas que descrevemos, vimos que os vendedores identificam os vizinhos que compram todos os meses; percebemos que eles detêm um conhecimento sobre as profissões dos compradores, ou ainda que se estabelecem entre eles diálogos baseados em interações anteriores. Um comprador regular expressa da seguinte maneira o seu vínculo com um vendedor:

Faz um ano que compro com ele todos os meses, seu ponto é muito próximo daqui e a gente estabeleceu uma relação. Comprei a revista e começamos a conversar. Passaram outros vendedores, mas ele me disse que esse ponto era dele. Além disso, a gente fez uma amizade. Não sei como ele foi parar na HBA mas agora eu o vejo bem, vejo uma pessoa que se alimenta, se preocupa com sua família. Sempre que ele vem, nós conversamos sobre muitas coisas: sobre a sua vida, sua família, sobre a minha etc. (Comprador da HBA, comerciante, 37 anos).

Outro registro de entrevista com um comprador nos oferece um sentido similar da subordinação do produto à identidade biográfica do vendedor.

Eu conheço a menina e a mulher dele, eu já dei roupa pra menina. Conversamos sobre a venda, sobre sua família, seus problemas. Ele faz um desconto pra mim na revista, mas na verdade eu compro de qualquer jeito (Comprador da HBA, empregado do comércio, 26 anos).

Em um de nossos encontros, um vendedor relatou como algumas pessoas do bairro que sempre compram a revista com ele fizeram uma coleta de dinheiro quando o seu filho adoeceu; além disso, conseguiu um trabalho temporário em um restaurante onde costuma vender a revista.

Nessas trocas, vemos que os vendedores da HBA estabelecem um vínculo por meio do qual podem mobilizar o compromisso dos compradores para com eles. Os vendedores fazem cumprir a seu favor uma obrigação gerada e 
mantida através de breves diálogos: lembrando que vai sair o número novo, realizando visitas mensais ao local de trabalho ou tão somente mostrandose no mesmo lugar regularmente. Este trabalho contínuo tem o objetivo de evitar que os compradores abandonem a troca. Talvez as relações com os compradores possam vir a transformar-se, ou já se transformaram em alguns casos, no que Mark Granoveter (1973) chama de "laços fracos fortes", isto é, aquelas relações de índole secundária que permitem aos sujeitos obterem recursos mais valiosos do que aqueles que poderiam ser obtidos entre seus pares ou vínculos primários. Estes laços podem assegurar não só uma regularidade na compra da revista mas, ocasionalmente, algum tipo de presente (geralmente comida e roupa) e, no melhor dos casos, uma oportunidade de trabalho para os vendedores. ${ }^{18}$

Como vimos ao longo desta parte do artigo, o dinheiro não está fixado numa esfera da troca, ou ligado a um tipo específico de vínculo social e oposto a outros. Ao analisarmos as diferentes articulações entre "coisas" e "pessoas" que ocorrem em torno desta circulação monetária, evitamos a confusão entre o meio de pagamento e a "forma de transferência". A mistura de "transação mercantil" e "transação monetária" teria impedido que percebêssemos corretamente os usos do dinheiro nas transferências sob a forma de dons. Como a evitamos, pudemos detectar como uma circulação monetária não se coloca em oposição aos vínculos pessoais, ao contrário, ela ajuda a criá-los e a mantê-los.

\section{Os aspectos ritualizados da venda: moral e dinheiro}

Se o dinheiro não define por si só a natureza das transferências entre vendedores e compradores, não deixa de ser certo também que sua utilização impõe algumas condições que estariam ausentes se somente outros objetos circulassem. Dois registros de entrevistas nos servem para ilustrar como as trocas entre vendedores e compradores não são indiferentes ao uso do dinheiro. No primeiro, um vendedor nos relatou como um comprador recusou-se a comprar a revista, mas aceitou comprar-lhe um sanduíche. No segundo, a compradora centrou seu argumento a favor da compra da revista com a seguinte afirmação: "Eu decido a quem ajudar, não sou de dar dinheiro a todo mundo que me pede". Ambas as situações dão conta de que o dinheiro pode, em alguns casos, converter-se em objeto de ajuda e, em outros, não; que existem pessoas que podem receber e outras não.

Segundo Ribert (2005), se a doação monetária se realiza, os doadores dificilmente deixam de emitir juízos sobre sua utilização e estabelecer algum 
tipo de controle, já que desta maneira reduzem a margem de autonomia que o dinheiro doado supõe. ${ }^{19}$ Se aportarmos esta perspectiva ao caso tratado neste artigo, nós nos depararemos com um enigma. Estamos diante de transferências regulares de dinheiro entre pessoas que têm um vínculo limitado no momento da compra-venda da revista. ${ }^{20}$ Como resolver a exigência de controle e os juízos sobre o uso do dinheiro na circulação monetária em relação aos vendedores? A resposta a essa pergunta encontra-se nos aspectos ritualizados da venda que traduzem a moralidade dos vendedores e, particularmente, suas obrigações em relação ao uso do dinheiro.

Em reiteradas ocasiões, os vendedores comentaram que é comum ouvir perguntas sobre suas trajetórias de vida, em especial sobre os eventos e as circunstâncias vinculados ao fato de estarem vivendo na rua. Os aspectos ritualizados da venda produzem as condições para introduzir na interação a possibilidade de que os vendedores se vejam "obrigados" a narrar alguns fragmentos de suas biografias. No contexto da "troca filantrópica", aqueles que recebem o dinheiro podem passar por situações em que seja necessário dar "provas de verdade" (Fassin 2000) sobre sua identidade social. "Como você chegou a esta situação?" — é a fórmula que ritualmente "abre" a intimidade dos vendedores, que resolverão, cada um a seu modo, como respondê-la. Se fosse uma outra cena de troca, sem dúvida esta frase seria considerada fora de lugar. No caso da venda da revista, esta pergunta é legítima e deve ser respondida através de narrativas de vida em conformidade com os aspectos rituais ligados à "troca filantrópica".

As cartas de leitores são um registro esclarecedor de como as narrativas biográficas dos vendedores intervêm nas relações face a face entre compradores e vendedores. Transcrevemos parte de uma delas:

Um dia, encontrei uma mulher sentada no meu muro. Foi um encontro de almas, ela era uma vendedora da HBA. Aprendi muito escutando-a. Talvez o que mais aprendi tenha sido sobre a incerteza desta vida [...] Alguém tem casa, alguém está na rua, mas nada é definitivo. Então, cada vez que cruzo com um vendedor, sinto uma imensa alegria e trocamos o que temos de trocar (Revista HBA, n.38).

Em outra carta é relatado o seguinte:

Queria contar que quando comprei a revista pela primeira vez entendi que quando a gente conhece as pessoas, a gente vê as coisas de forma diferente. Porque a gente costuma se guiar pela primeira impressão sobre as pessoas da rua. O homem que me vendeu a revista era muito gentil e simpático e me contou 
que não teve outras oportunidades de trabalho em sua vida. [...] Agora sei que as pessoas da rua não estão na rua porque querem. (Revista HBA, n.32).

A relação face a face com o vendedor permitiu que esta compradora mudasse sua concepção sobre as pessoas da rua. As primeiras impressões levaram-na a adotar um preconceito: as pessoas da rua estão na rua porque querem. O novo ponto de vista sobre esta categoria social baseia-se no tratamento que recebeu do vendedor - simpático e gentil - e no relato que ele fez de alguns fragmentos da sua vida. Em outra carta descreve-se a seguinte relação face a face:

Tive a oportunidade de encontrar um vendedor da HBA [...] a verdade é que vêlo me causou a alegria de quem encontra um amigo que há muito não via [...] Me emocionei ao escutar este homem me contar, com profundo orgulho, em que consistia seu trabalho e como tinha mudado a sua vida (Revista HBA, n.21).

Estas cartas afirmam a existência de um núcleo comum nas relações face a face relatadas pelos compradores. A mudança na opinião sobre as pessoas da rua - que se produz a partir do tratamento gentil e da simpatia de um vendedor - ou os sentimentos que nascem diante do orgulho com que um membro da HBA conta como mudou sua vida desde que começou a vender a revista, enquadram-se em um ritual que põe à disposição dos vendedores elementos comunicativos que buscam marcar a "distinção" ou o "mérito" no universo dos "necessitados". Deste ponto de vista, as exposições públicas dos vendedores não evitam destoar da promoção da "troca filantrópica".

No seguinte fragmento de entrevista, um vendedor reconstrói o seu relato quando os compradores lhe perguntam sobre a venda ou sobre a sua vida cotidiana. Nesta reconstrução da exposição de si diante dos compradores, o vendedor dá especial ênfase ao uso do dinheiro para marcar sua "distinção" ou "mérito".

[Sempre conto aos compradores que] eu quero seguir em frente, senão eu estaria pedindo esmola. Somos vários os vendedores e encaramos a revista como um trabalho. E é com esse trabalho que a gente paga a pensão, se mantém, e bom, quando dá, compra uma roupa. Ou seja, a gente não ganha uma fortuna, mas a gente se mantém e encara isso como um trabalho, um trabalho digno. Para mim é um trabalho: não é que as pessoas vejam a sua cara de coitado e te dêem uma moeda por isso (Vendedor da HBA, 53 anos). 
Se os aspectos rituais da venda organizam uma exposição de si baseada no "mérito", também prescrevem o tipo de obrigações que os vendedores devem cumprir para receber o dinheiro dos compradores. O comentário seguinte expressa estas ramificações entre dinheiro e obrigações.

Tento comprar, mesmo que seja uma revista por mês, todos os meses, porque acho um bom projeto, os vendedores não têm nenhum compromisso conosco, têm com eles mesmos: vender e cuidar-se um pouco (Comprador da HBA, docente, 49 anos).

Os diálogos entre os compradores e os vendedores - registrados em cenas de troca, nas entrevistas e nas cartas de leitores - costumam centrarse em aspectos ligados ao "cuidado de si" dos segundos, como demonstra os seguintes fragmentos de entrevistas.

A única coisa que dizem é: "Espero que você continue neste caminho". Eles querem te ver bem. Sabem que tem tanto vagabundo, tanto álcool (Vendedor da HBA, 70 anos).

As pessoas que compram te perguntam: "Como você está?". Eles gostam que você suba um degrau, que você progrida (Vendedor da HBA, 25 anos).

As palavras de um comprador para um vendedor destacando seu estado de ânimo -hoje te vejo bem, te vejo pra cima - a transcrição de um fragmento de entrevista em que um comprador fala sobre um membro da HBA - eu o vejo bem, se alimenta, se preocupa com sua família - ou a carta de um leitor em que a compradora se emociona com a mudança na vida do vendedor são registros de que os sinais que os vendedores dão sobre o "cuidado de si" e a avaliação que os compradores fazem deles estão presentes nessas relações face a face, portanto, na circulação monetária que analisamos.

Os sinais contrários à obrigação do "cuidado de si" que ele prescreve ameaçam a continuidade das trocas entre os compradores e os vendedores. Diante da recusa em aceitar o marco ritual de compra-venda da revista, os vendedores usam um registro mais próximo ao da "mendicância", sem a "circunspecção" dramática que a "troca filantrópica" exige. Quando ocorrem estas cenas, a diferença entre pedir e vender a revista é nula. Assim, a "mendicância" não organiza uma cena social que permita afiançar a figura pública dos vendedores ligada às categorias da "dignidade" ou do "esforço".

Deixar de trocar pode ser o resultado do descontentamento produzido por certas circunstâncias, sobretudo a que chamamos de "indisciplina dra- 
mática" dos vendedores: estar alcoolizado, brigar, agredir um comprador etc. Assim, contar a um outro vendedor que não compra a revista por causa destes fatos e ligar para a organização para denunciar um vendedor são atos que demonstram como a "indisciplina dramática" põe em risco a troca ao se apresentarem sinais contrários à obrigação prescrita na "troca filantrópica". Os testemunhos seguintes expressam este ponto de vista.

As pessoas dizem que nós vendemos a revista para depois comprar vinho, e nos vêem assim. Muitas vezes, aconteceu de me avisarem que tinham encontrado um companheiro meu jogado no chão com todas as revistas esparramadas (Vendedor da HBA, 55 anos).

Lamentavelmente, já me aconteceu oferecer a revista e a pessoa me dizer: "Olha, tem um companheiro teu que está vendendo a revista, teve um mau comportamento e eu não quis comprar dele porque me tratou mal". Você prejudica a revista, prejudica a nós (Vendedor da HBA, 50 anos).

Os vendedores que adotam um trato personalizado com os compradores têm a vantagem de jogar a seu favor este vínculo para protegê-los da mudança de circunstâncias que poderia ameaçá-los. Por sua vez, as obrigações próprias do ritual requerem maior compromisso por parte dos vendedores, já que eles são avaliados para que haja continuidade nas transações. Como nos dizia um vendedor que tinha uma clientela fixa: "Você não pode decepcionar estas pessoas (os compradores) que te dão essa confiança. Se eles te dão força, você tem que retribuir, tem que respeitar as pessoas".

Mas em muitos casos as possibilidades de salvar a troca são escassas. Lembremos daquela frase de um vendedor ao se referir a um colega: "Apesar de seus esforços, os encrenqueiros arruínam constantemente seu ponto, porque 'queimam sua imagem'". A troca fica ameaçada quando perde o sustentáculo de seu "encanto": a credibilidade da organização e o "credenciamento" moral da figura do vendedor da HBA.

As expectativas sobre as obrigações dos vendedores orientam-se também para a organização, a qual "garante" a existência da "troca filantrópica". Ainda que na maioria dos casos a relação com a HBA se dê somente através da informação que a revista oferece e do contato com os vendedores, os compradores destinam seu dinheiro pressupondo que seu uso está garantido pela organização. Esta suposição aparece nas entrevistas da seguinte maneira,

[Eu deixaria de comprar] caso ela se convertesse num projeto comercial. Talvez o único compromisso seja que a HBA continue sendo um projeto coletivo, 
estruturado para e pela melhoria das condições de muita gente. Se a HBA deixasse de ter esse objetivo, perderia sentido para mim (Comprador da HBA, funcionário administrativo, 30 anos).

Como retrata este trecho da entrevista, se a revista não fosse vendida por pessoas em "dificuldades" no contexto de uma "troca filantrópica", que garante o uso do dinheiro para ajudar os vendedores, os compradores não se veriam comprometidos em adquiri-la.

Definitivamente, a circulação monetária depende da "dramatização" da obrigação referida à "maneira" de obter e usar o dinheiro. A forma "trabalho" e a forma "cuidado de si" são aspectos rituais que permitem que os vendedores se "credenciem" moralmente. Assim, o dinheiro transferido diferencia e hierarquiza os vendedores diante daqueles que empreendem outras "maneiras" de ganhar dinheiro (mendicância) ou de usá-lo (consumo de drogas, de álcool etc). Este "credenciamento", como vimos, repousa também no "cuidado" das expectativas ligadas à outra "forma" de circulação monetária da "troca filantrópica": a da organização em relação aos vendedores.

\section{Palavras finais. Sobre dons e usos sociais do dinheiro}

Por força das dicotomias que estão na origem da teoria social moderna (comunidade/sociedade; solidaridade orgânica/solidaridade mecânica; sociedade moderna/ sociedade tradicional, entre outras), o dinheiro ficou do lado dos mecanismos racionais, impessoais e objetivos de vinculação social. A estas equivalências costumam opor-se os mecanismos emocionais, pessoais e subjetivos que entrelaçam as pessoas. Ao se excluir o dinheiro deste último jogo de equivalências, nublam-se os significados de seu uso, em especial sua dimensão normativa. Quando esta é levada em conta, isso é feito para determinar, com ancoragens morais, o pano de fundo "irracional" ou "residual" da circulação monetária. Em um contexto em que as imagens desses universos dicotomizados são altamente questionadas, é de se esperar que o papel do dinheiro na construção dessas oposições também o seja. Desse ponto de vista, o uso do dinheiro afasta-se da exclusiva esfera racional, impessoal e objetiva para poder ser observado e analisado em outras cenas sociais, permitindo o questionamento aos dois jogos de equivalências que o essencializam.

Nosso propósito foi mostrar, a partir da experiência das publicações de rua, as circunstâncias que fazem do dinheiro uma "moeda especial" e, em particular, como sua circulação está ancorada em determinados princípios de legitimidade, classificações morais e marcos rituais. Parece-nos que, ao 
condenar moralmente a monetarização de uma esfera ou vínculo social que deveria estar ao abrigo do uso do dinheiro, abandona-se a reflexão sobre os contornos específicos das práticas da doação e dos circuitos filantrópicos.

Nosso artigo, pelo contrário, apresentou a qualidade social do dinheiro. Para isso, levamos em conta que seu uso não define necessariamente um tipo de vínculo ou esfera de troca. Também mostramos as obrigações que o uso do dinheiro supõe em determinados contextos. Estes dois níveis, que à primeira vista parecem contraditórios (um nível que "descentra" e outro nível que "recentra" o dinheiro em relação aos vínculos, às interações e às práticas sociais), marcam os limites em que o dinheiro se objetivaria enquanto fato social.

Em função de nossa análise ter se desenvolvido no terreno marcado por estes dois limites, foi possível mostrar uma série de elementos capazes de determinar que a significação social do dinheiro não repousa unicamente na sua qualidade de meio de pagamento. De fato, analisamos o dinheiro circulando entre diferentes vínculos sociais, organizando diversos tipos de troca, gerando e mantendo relações pessoais; por fim, apresentamos como a circulação do dinheiro se "entrelaça" a uma série de prescrições simbólicas e morais que diferenciam e hierarquizam as "pessoas".

Finalmente, gostaríamos de estabelecer uma reflexão sobre a fronteira entre as "transações mercantis" e as "circulações de dons". Este trabalho nos permite pensar que esta diferenciação pode ser abordada bem mais a partir da perspectiva da "reversibilidade" e da "contigüidade" do que a partir da ótica da oposição. Os registros de campo assinalam como o entrelaçamento entre as "pessoas" e as "coisas" é reversível nas trocas. Por um lado, encontramos aqueles que narram a sua surpresa ao se depararem com uma revista que é boa, apesar de ter sido comprada, sobretudo, com fins solidários. Por outro lado, os registros de campo mostram a existência de compradores regulares que adquiriram a HBA pela chamada da matéria de capa e, em seguida, começaram a comprá-la habitualmente quando compreenderam mais sobre quem as vende ou sobre a organização que a produz. Como vemos, as trocas tornam-se reversíveis: passam do interesse no produto ao compromisso com o vendedor, e vice-versa.

A "contigüidade" surge ao comprovar em nossas descrições que os vendedores se ajustavam a cenas sociais que remetiam a diferentes tipos de troca. Ao longo de um dia, registrávamos que um mesmo vendedor podia obter seu dinheiro intercalando transações mercantis ou trocas organizadas em função de sua identidade social ou biografia. Essas cenas eram geralmente realizadas por um mesmo vendedor com diversos compradores, estabelecendo-se a "contigüidade" entre elas e ajustando-se às diferentes trocas. 
Se tivéssemos adotado uma perspectiva rígida, que opõe as "transações mercantis" às "circulações de dons", não teríamos compreendido como se operam essas passagens permanentes entre cenas sociais que são transformadas pela "reversibilidade" e "contigüidade" das trocas que analisamos.

Recebido em 10 de outubro de 2006

Aprovado em 27 de abril de 2007

Tradução de Maria José Alfaro Freire

Ariel Wilkis é bolsista do Consejo Nacional de Investigaciones Científicas y Tecnológicas, docente da Universidad de Buenos Aires e doutorando em sociologia na Universidad de Buenos Aires e na École des Hautes Études en Sciences Sociales. E-mail: arielwilkis@sinectis.com.ar

\section{Notas}

· Agradeço os comentários, as sugestões e as críticas às diferentes versões deste texto feitas por Alexandre Roig, Cecilia Cross, Leandro Lopez e Lygia Sigaud. Também foram de suma utilidade os comentários dos leitores anônimos que avaliaram este artigo.

${ }^{1} \mathrm{O}$ conceito utilizado para referir-se a este processo é o de "mercado do dom". Para rastrear estas transformações no mundo filantrópico francês, ver Salomon (1998) e Dufourcq (1996). Para o caso argentino, uma análise geral foi realizada em Grassi (2003).

${ }^{2}$ Utilizamos os termos transferência (e circulação) para assinalar a existência de uma mudança na posse de objetos; os conceitos de "transações mercantis" e "circulações de dons" remetem a um nível de interpretação sobre o sentido e a lógica dessa mudança. Existem diferentes "formas" de transferências. Esta idéia de "forma" de transferência, eu a retomo de Testart (2001).

${ }^{3}$ Muitas das respostas positivas a esta pergunta se baseiam na idéia de que o dinheiro corrompe a esfera das doações, porque supõe compromissos frágeis e obrigações mínimas por parte dos doadores, e também dos receptores (Lipovetsky 1992). A subestimação do ato de doar liga-se a uma classificação moral na qual o uso do dinheiro nas doações se aproxima ao de qualquer mercado. Daí a sua censura por 
orientar-se através do "interesse", do proveito, da utilidade etc. "As ONGS — assim como a igreja ou qualquer outra instituição que se move na economia da oferenda (ou da caridade) e do voluntariado (ou do sacrifício) - não podem ignorar a lógica do mercado. Assim, as doações não deixam de ser transações que se contabilizam em termos monetários" (Picas Contreras 2003:3).

${ }^{4}$ Zelizer (2005a) analisa o uso do dinheiro para fins domésticos, filantrópicos e enquanto objeto de presente nos EUA, no final do século XIX e princípio do século XX. Seus achados demonstram como a crescente monetarização da vida social americana não implicou tratar o dinheiro como um mediador universal, abstrato e impessoal mas, ao contrário, nessas diferentes cenas e contextos, seu uso estava ancorado em dimensões sociais e morais. Na sua perspectiva, não se pode pensar o dinheiro como um objeto único, uniforme e generalizável, mas sim perceber que existem "moedas múltiplas" que se diferenciam socialmente por meio de marcos interacionais e rituais (Zelizer 1989, 2005a).

${ }^{5}$ Mauss reconhece a imprecisão do termo dom, assim como seu caráter "híbrido" (Mauss 1997:267). Estas imprecisões são a fonte de interpretações opostas sobre o "Ensaio sobre o dom". Tanto os que afirmam a oposição entre mercadoria e dom (Polany, Gregory), quanto os que sustentam sua complementaridade (Bourdieu, Appadurai) apóiam-se na leitura deste texto "clássico", como é assinalado por Berthoud (1991).

${ }^{6}$ No texto as palavras em itálico fazem referência aos termos nativos dos agentes.

${ }^{7}$ Neste artigo, não colocarei em questão a diferença entre "transações mercantis" e a "circulação de dons" (Appadurai 1995), e tampouco sustentarei que existe uma "oposição lógica" entre elas (Gregory 1997). Meu objetivo é problematizar, a partir de minha etnografia, a equivalência entre dinheiro-transação mercantil e a oposição entre dinheiro-dom.

${ }^{8}$ Green (1999) assinala que os antecedentes dessas experiências encontram-se em uma série de publicações realizadas pelo Exército da Salvação dos EUA no final do século XIX e início do XX, e em uma revista, The Hobo News, editada entre 1910 e 1920.

${ }^{9}$ Diferentes trabalhos analisaram estas organizações, as quais se encontram em diferentes países. Ver Damon (1995); Tork (2001); Swithinbank (2001); Howley (2003) e Frétigné (2004).

${ }^{10}$ Existem casos particulares a mencionar que apontam para a proliferação dessas organizações. Na Alemanha, chegaram a existir 35 publicações, formando-se uma rede nacional. Em Amsterdã, cerca de 10 publicações circulavam em fins dos anos 90, e nos EUA calculava-se, para a mesma época, a existência de 70 publicações em diferentes cidades (Tork 2001).

${ }^{11}$ Além da HBA, vende-se também na cidade de Buenos Aires a revista Diagonal. No resto do país existem outras publicações semelhantes vendidas por desempregados, "meninos de rua" etc. 
${ }^{12}$ Os "abrigos" ("hogares") são instituições estatais ou privadas — geralmente de origem confessional — destinadas a receber durante a noite aqueles que não têm onde dormir.

${ }^{13}$ Este número tinha como título "Andá a laburar" ("Vai trabalhar") e como subtítulo, "Este es mi trabajo" ("Este é meu trabalho").

${ }^{14}$ Com base nas fichas de inscrição que são preenchidas quando um novo vendedor entra na organização, obtivemos informação sobre a evolução dos inscritos durante o período de fevereiro de 2001 a fevereiro de 2004. No total, 1.384 fichas foram analisadas. Os inscritos são, em sua maioria, homens (73,3\%). Os dados descrevem um universo de pessoas que vivem, majoritariamente, em condições habitacionais sumamente precárias: 32,9\% declararam viver principalmente na rua; $23,5 \%$ em pensões e hotéis; 7,5\% em abrigos e refúgios; $13,8 \%$ em casas ou apartamentos (próprio/alugado); 4,9\% em lugares emprestados e $2 \%$ em outros.

${ }^{15}$ Os nomes foram alterados para preservar o anonimato dos vendedores.

${ }^{16}$ A partir da análise de 37 números da revista — de junho de 2001 a dezembro de 2004 - distingui os seguintes temas recorrentes nas primeiras páginas: promoção de artistas (22 números), apresentação de temas vinculados a problemáticas sociais (11 números) e informações sobre a HBA (4 números), principalmente nos aniversários da organização, e um número de fim de ano sobre a vida cotidiana dos vendedores.

${ }^{17}$ Segundo Florence Weber (2000), as transações mercantis organizam-se em torno da equivalência reconhecida entre um objeto e seu preço.

${ }^{18}$ Uma análise similar à minha encontra-se em Cartier (2000). A autora analisa a venda de calendários de fim de ano por parte dos carteiros franceses. Assim como em meu caso, nestas cenas de compra-venda misturam-se transações monetárias e vínculos pessoais. Ao retomar Bourdieu, Cartier denomina de "trabalho de sociabilidade" as práticas dos carteiros dirigidas a se manter o vínculo com os compradores dos calendários.

${ }^{19}$ Este argumento baseia-se na conceituação de Simmel (1987) do dinheiro como um "meio para tudo e de todos", que o distingue de outros valores e que permite um uso ilimitado para adquirir bens.

${ }^{20} \mathrm{Em}$ alguns casos, o grau de interconhecimento pessoal entre vendedores e compradores é mais elevado do que em outros, mas mesmo estes vínculos não se aproximam daqueles analisados por Ribert — relações de parentesco. 


\section{Referências bibliográficas}

APPADURAI, Arjun. 1995. "Introduction: commodities and the politics of value". In: (org.), The social life of things: commodities in cultural perspective. Cambridge: Cambridge University Press. pp.3-63.

BERTHOUD, Gerard .1991. "Le marché comme simulacre du don". Revue M.A.U.S.S, 11:72-89.

BLOCH, Maurice \& PARRY, Jonathan (orgs.).1989. Money and morality of exchange. Cambridge: Cambridge University Press.

BLOCH, Maurice. 1989. "The symbolism of the money in Imerina". In: M. Bloch \& J. Parry, (orgs.), Money and morality of exchange. Cambridge: Cambridge University Press. pp.165-189.

CARRIER, James. 1992. "Occidentalism: the word turned upside-down". American Ethnologist, 19(2):195-212.

CARTIER, Marie. 2000. "Le calendrier $\mathrm{du}$ facteur. Les significations sociales d'un échange anodin". Genèses, 41:63-84.

DAMON, Julien .1995. "Les journaux de rue. Usage social d' un handicap économique, ou usage économique d'un handicap social?". Revue Française des Affaires Sociales, 49(2-3):53-78.

DUFOURCQ, Nicolas (org.).1996. L'argent du cœur. Paris: Hermann.

FASSIN, Didier. 2000. "La supplique. Stratégies rhétoriques et constructions identitaires dans les demandes d'aide d' urgence". Annales, Histoire, Sciences Sociales, 19(5):955-981.

FRETIGNE, Cédric. 2004. Les vendeurs de la presse SDF. Paris: L'Harmattan.

GRASSI, Estela. 2003. Políticas y problemas sociales en la sociedad neo- liberal. Buenos Aires:Editorial Nuevo Espacio.

GREEN, Norma. 1999. "Traying to write a history of the role of street newspapers in the social movement to alleviate poverty and homelessness". Ver em www.depts.washington.edu/stnews/green. Acessado em 10/03/2005.

GREGORY, Chris. 1997. Savage money: the Anthropology and politics of commodity exchange. Amsterdam: Harwood Academic Publisher.

HOWLEY, Kevin. 2003. "A poverty of voices. Street papers as communicative democracy". Journalism, 4(3):273-292.

LIPOVETSKY, Gilles. 1992. Le crépuscule du devoir - L'éthique indolore des nouveaux temps démocratique. Paris: Gallimard.

MALINOWSKI, Bronislaw. 1986. Los argonautas del pacifico occidental. Un estudio sobre el comercio y aventura de los indígenas de los archipiélagos de la Nueva Guinea Melanésica. Buenos Aires: Planeta.

MAUSS, Marcel. 1997. "Essai sur le don: forme et raison de l'échange dans les sociétés archaïques". In : Sociologie et Anthropologie. Paris: PUF. pp. 142-279.

PARRY, Jonhatan. 1986. "The gift, the indian gift and the 'indian gift'". Man, 21(3):453-473.

PICAS CONTRERAS, Joan. 2003. "Las ONG's y el mercado de la caridad". Revista electrónica Quaderns-e, 1. Ver em: www.icantropologia.org/quaderns-e/01/01a08txt.htm. Acessado em 3/04/2005.

RIBERT, Evely. 2005. "Dire la dette travers l'argent ou la taire à travers le 
don. Les allocataires du RMI et l'aide monétaire". Terrain, 45:53-66.

RUONAVAARA, Hannu. 1997. "Moral regulation: a reformulation". Sociological Theory, 15(3):277-293.

SALOMON, Jean-Marc. 1998. Le désire de société. Des restos du cœur au mouvement des chômers. Paris: Editions La Découverte.

SIMMEL, Georg. 1987. Philosophie de l'argent. Paris: PUF.

SWITHINBANK, Tessa. 2001. Coming up from the streets. The story of the Big Issue. Londres: Earthscan Publications.

TESTART, Alain. 2001. "Echange marchand, échange non marchand". Revue Française de Sociologie, 42:719-749.
TORK, Daniele. 2001. "Voices of the homeless people in street newspapers: a cross-cultural explorations". Discourse and Society, 12( 3):371392.

WEBER, Florence. 2000. "Transactions, marchandes, échanges rituels, relations personnelles. Une ethnographie économique après le grand partage". Genèses, 41:85-107.

ZELIZER, Viviana. 1989. "The social meaning of money: special monies". American Journal of Sociology, 95:342-377.

. 2005a. La signification sociale de l'argent. Paris: Editions du Seuil. . 2005b. "Intimité et économie". Terrain, 45:13-28. 


\section{Resumo}

A partir de um estudo de caso centrado em uma organização que edita uma revista vendida por pessoas "sem teto" na cidade de Buenos Aires, me interrogo sobre os usos sociais do dinheiro em circuitos filantrópicos. Ao seguir a polêmica entre dinheiro e dom, que está no centro das discussões da antropologia e da sociologia, enfoco duas questões: a) o papel do dinheiro para demarcar os limites entre as "transações mercantis" e as "circulações de dons"; b) a relação entre dinheiro e moral. O trabalho de campo consistiu em uma etnografia das transações entre os vendedores e os compradores desta publicação.

Palavras-chave: Dinheiro, Dons, Filantropia, Antropologia das trocas sociais

\section{Abstract}

Based on a case study of an organization responsible for publishing a magazine sold to 'homeless' people in Buenos Aires, I examine the social uses of money in philanthropic circles. Turning to the polemic between money and gift at the centre of discussions in anthropology and sociology, I focus on two questions: a) the role of money in demarcating the limits between 'market transactions' and 'gift circulations'; b) the relation between money and morality. Fieldwork involved an ethnographic study of the transactions between the sellers and buyers of this publication.

Key words: Money, Gifts, Philanthropy, Anthropology of Social Exchanges 